\title{
Nebulized heparin in Burkholderia cepacia colonized adult cystic fibrosis patients
}

\author{
M. Ledson, M. Gallagher, C.A. Hart, M. Walshaw
}

\begin{abstract}
Nebulized heparin in Burkholderia cepacia colonized adult cystic fibrosis patients. M. Ledson, M. Gallagher, C.A. Hart, M. Walshaw. (C) ERS Journals Ltd 2001.

ABSTRACT: Viscous negatively charged cystic fibrosis (CF) sputum allows colonization by pathogens, inducing a chronic inflammatory response. Heparin thins sputum by decreasing the mucin molecule amino group negative charge, altering its intermolecular hydrogen bonding, and ionically shielding its polyionic moieties. It also has an anti-inflammatory effect within the lung. It may, therefore, be useful in the treatment of $\mathrm{CF}$ patients.

In order to test this, six fully informed Burkholderia cepacia colonized stable adult CF patients, received 25,000 IU nebulized heparin sulphate daily for 7 days. Subjective sputum parameters, spirometry, platelets, coagulation parameters, and serum and sputum interleukin (IL)-6 and -8 were measured before and after treatment.

All patients tolerated the heparin with no evidence of bleeding, thrombocytopenia or change in coagulation parameters. There was no change in spirometry, but a reduction in interleukins (sputum IL-6, $p=0.01$; sputum IL-8, $p=0.002$; serum IL-6, $p=0.02$; serum IL-8, $p=0.02)$. Sputum was easier to expectorate $(p<0.04)$, with a trend towards thinner sputum $(p=0.07)$ but no change in sputum volume.

Heparin therapy was well tolerated and had an anti-inflammatory effect, with subjective sputum mucolysis. Further studies are necessary to define the role of heparin in the treatment of cystic fibrosis patients.
\end{abstract}

Eur Respir J 2001; 17: 36-38.

The Regional Adult Cystic Fibrosis
Unit, The Cardiothoracic Centre, Unit, The Cardiothoracic
Thomas Drive, Liverpool, UK.

Correspondence: M Walshaw, The Regional Adult Cystic Fibrosis Unit, The Cardiothoracic Centre, Thomas Drive, Liverpool, UK Fax: 441512932331

\section{Keywords: Burkholderia cepacia cystic fibrosis heparin sulphate}

\section{Received: May 292000}

Accepted after revision October 182000
The genetic defect in cystic fibrosis (CF) allows the production of abnormally sticky mucus, which, in the respiratory tract, results in colonization by pathogenic bacteria and ensuing chronic infection [1]. These bacteria initiate an influx of inflammatory cells, which release high levels of inflammatory cytokines (such as interleukin (IL)-6 and -8), which in turn encourage the recruitment of more inflammatory cells, resulting in a vicious circle of chronic respiratory infection and inflammation [2]. It is this pulmonary inflammatory cycle that is the major cause of morbidity and mortality in $\mathrm{CF}$ patients. There is evidence that this cycle is further exaggerated in those patients colonized by Burkholderia cepacia, where levels of lung inflammation can be up to ten times that seen with Pseudomonas aeruginosa [3]. As a consequence of this, B. cepacia colonized patients have a more rapid loss of lung function and greatly increased mortality [4]. Agents that thin sputum or possess anti-inflammatory effects may, therefore, be beneficial in the treatment of lung disease in these $\mathrm{CF}$ patients.

Heparin sulphate has such mucolytic and antiinflammatory actions [5]. It has been used safely in nebulized form by patients with asthma [6] but there is no experience in patients with cystic fibrosis. Therefore, the effect of nebulized heparin sulphate on inflammatory markers and sputum viscidity in CF patients chronically colonized by UK epidemic (ET12) $B$. cepacia, was assessed.

\section{Patients and methods}

Following local Ethical Committee approval, six fully informed UK epidemic B. cepacia colonized adult CF patients (mean age 27.7 yrs (range 21-34), four male), received 25,000 IU nebulized heparin sulphate for 7 days. The heparin was diluted with $5 \mathrm{~mL}$ of normal saline and taken via a mouthpiece using a CR50 nebulizer (Medicaid, Bognor Regis, UK). All patients had their usual bronchodilator therapy and performed their usual chest physiotherapy before administering heparin. The first dose was given under medical supervision in hospital and the patient was observed for $30 \mathrm{~min}$ to ensure bronchospasm did not develop.

The following parameters were measured immediately before and after the trial period: 1) platelet count and coagulation parameters; 2) serum IL-6 and IL-8 levels, using a microtitre plate enzyme linked immunosorbent assay (ELISA) method (Medgenix, UK); 3) sputum IL-6 and IL-8 levels; 4) spirometry (forced expiratory volume in one second (FEV1)\% predicted); and 5) subjective sputum parameters using a visual analogue score (VAS) on a $0-10$ scale, where for repeat 
testing, patients were blinded to their previous responses.

\section{Statistics}

All data were analysed using a Wilcoxon signed rank test for nonparametric values. A p-value of $\leqslant 0.05$ was considered statistically significant.

\section{Results}

All patients tolerated the nebulized heparin with no evidence of bleeding or thrombocytopenia (mean platelet count $\left(\times 10^{9} \cdot \mathrm{L}^{-1}\right)$ : pre 274.8 versus post 287.4 , $\mathrm{p}=\mathrm{NS}$; mean International normalized ratio pre 1.0 versus post $0.9, \mathrm{p}=\mathrm{NS}$; mean active partial prothrombin time pre 27.4 versus post 27.4, $\mathrm{p}=\mathrm{NS}$ ). There was a reduction in sputum and serum IL-6 and IL-8 levels (fig. 1). Based on the VAS, patients found sputum easier to expectorate $(p<0.04)$, with a trend towards thinner sputum $(p=0.07)$ but no change in sputum volume $(\mathrm{p}=0.12)$ (table 1). There was no change in spirometry (table 1).

\section{Discussion}

Uninfected sputum is a complex mixture of mucous glycoproteins, water, low molecular weight ions, proteins and lipids. Its structure depends upon the presence of intramolecular disulphide bonds, macromolecular entanglements, hydrogen bonding, ionic interactions between negatively charged moieties, and the presence of extracellular deoxyribonucleic acid (DNA) and actin filaments [7]. Sputum viscoelasticity is increased in $\mathrm{CF}$ due to the presence of abnormal amounts of DNA, abnormal hydration, and the abnormal sulphonation of glycoproteins [7]. Several therapies have been used to thin CF sputum: recombinant human deoxyribonuclease (rhDNase) cleaves extracellular DNA, acetylcystine disrupts glycoprotein disulphide bonds, and hypertonic saline improves

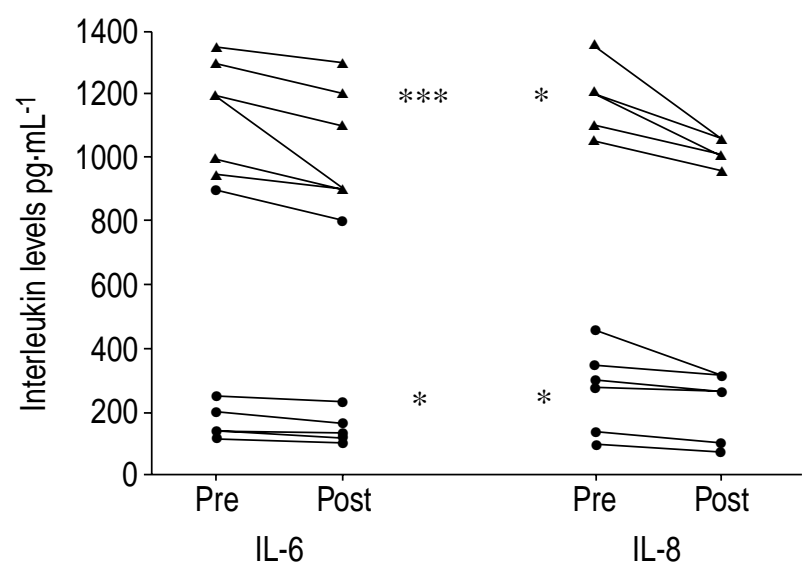

Fig. 1. - Change in serum (O) and sputum ( $\boldsymbol{( \boldsymbol { O } )}$ interleukins with heparin therapy. IL-6: interleukin-6; IL-8: interleukin-8. *: $\mathrm{p}<0.02$, pre versus post; ***: $\mathrm{p}<0.001$, pre versus post. mucus hydration. Thus, all these agents have a single mode of action. Heparin however, may thin sputum by several mechanisms. Firstly, it decreases the interaction of the negative charge on the amino groups of the mucin molecule, thereby reducing its entanglement with neighbouring sulphate groups. Secondly, it interferes with intermolecular hydrogen bonding due to its small molecular weight. Thirdly, its sodium ionically shields the polyionic moieties of the mucin molecule [8]. The present study confirms the mucolytic effect of heparin, since the patients found their sputum significantly easier to expectorate with a trend towards thinner sputum after only 1 week of treatment.

In the lung, exposure to bacterial pathogens stimulates epithelial cells and monocytes to produce the proinflammatory cytokines IL-6 and IL-8 [2]. These cause an influx of neutrophils and macrophages into the small airways to combat the infection. The free radicals and proteolytic enzymes they produce form part of the natural inflammatory response. However, in the abnormal pulmonary environment found in the $\mathrm{CF}$ lung, chronic colonization with pathogenic bacteria causes a florid, prolonged and excessive stimulation of proinflammatory cytokines. The size of the inflammatory response depends upon the organism involved; $B$. cepacia induces proinflammatory cytokines to a level ten times higher than that of $P$. aeruginosa and levels of inflammation are significantly higher during $B$. cepacia exacerbations compared to those of $P$. aeruginosa [3]. Furthermore, B. cepacia lipopolysaccharide is a potent stimulator of the neutrophil respiratory burst, and free neutrophil elastase can be found in high concentrations in the broncheoalveolar lavage fluid of infected patients [1]. By overwhelming the antiproteinase defences, neutrophil elastase causes lung injury by degrading elastin and collagen.

Heparin has an anti-interleukin activity and binds to both IL-6 and IL-8 [9]. It interferes with the key first step in leukocyte recruitment from the vasculature to the site of inflammation in animal models of peritonitis [10] and attenuates neutrophil chemotaxis [11]. It has also been shown to reduce the respiratory burst of neutrophils in a concentration dependant manner [12]. Finally, heparin has been shown to potentiate the association between proteinase inhibitors and human leukocyte elastase, hastening elimination of the enzyme [13]. In the present study, a significant decrease in sputum and serum IL-6 and IL-8 levels had occurred within 7 days. Further studies are required to determine the effects of more prolonged administration on other inflammatory markers, and more importantly, on lung function.

Intravenous or subcutaneous heparin has anticoagulant properties and can cause idiosyncratic thrombocytopaenia [14]. However, nebulized heparin is an ideal route for the treatment of lung inflammation and when previously given in this manner to asthmatics, caused low serum concentrations without evidence of coagulation disturbance or thrombocytopaenia [15]. In keeping with this, none of the patients had any evidence of disturbance of clotting parameters or platelet levels. Nevertheless, a previous history of severe haemoptysis would be seen as a contraindication to inhaled heparin therapy in this patient group. 
Table 1. - Spirometry and subjective sputum changes with heparin therapy

\begin{tabular}{lccc}
\hline Parameter & Pretherapy & Post-therapy & p-value \\
\hline FEV1 \% pred & $55.0 \pm 4.8$ & $56.3 \pm 6.6$ & 0.34 \\
Ease of sputum expectoration VAS* & $4.6 \pm 0.55$ & $6.8 \pm 0.60$ & 0.04 \\
Sputum thickness VAS & $4.1 \pm 0.41$ & $6.3 \pm 0.72$ & 0.07 \\
Sputum volume VAS & $4.8 \pm 0.60$ & $6.3 \pm 0.67$ & 0.12 \\
\hline
\end{tabular}

Data are presented as means \pm SEM. FEV1: forced expectoratory volume in one second; VAS: visual analogue scale. *: $0=$ hardest, $10=$ easiest; ${ }^{\#}: 0=$ thickest, $10=$ thinnest; ${ }^{\uparrow}: 0=$ most, $10=$ least.

Thus, in this pilot study, nebulized heparin was well tolerated, and had an anti-inflammatory action with subjective sputum mucolysis. Further studies are required to determine both the long-term clinical effects and safety of this therapy.

\section{References}

1. Govan JR, Deretic V. Microbial pathogenesis in cystic fibrosis: mucoid Pseudomonas and Burkholderia cepacia. Microbiol Rev 1996; 60: 539-574.

2. Bonfield TL, Panuska JR, Konstan MW, et al. Inflammatory cytokines in cystic fibrosis lungs. $\mathrm{Am}$ J Respir Crit Care Med 1995; 152: 2111-2118.

3. Shaw D, Poxton JR, Govan JRW. Biological activity of Burkholderia (Pseudomonas) cepacia lipopolysaccharide. FEMS Immunol Med Microbiol 1995; 11: 99-106.

4. FitzSimmons S. The cystic fibrosis foundation patient registry report. Pediatr Pulmonal 1996; 21: 267-275.

5. Tyrell DJ, Horne AP, Holme KR, Preuss JMH, Page CP. Heparin in inflammation: potential therapeutic applications beyond anticoagulation. Adv Pharmacol 1999; 46: 151-208.

6. Diamant Z, Timmens MC, van der Veen $\mathrm{H}$, Page CP, van der Meer FJ, Sterk PJ. Effect of inhaled heparin on allergen-induced early and late asthmatic responses in patients with atopic asthma. Am J Respir Crit Care Med 1996; 153: 1790-1795.

7. Geddes DM. Future prospects. In: Hodson ME,
Geddes DM, eds. Cystic Fibrosis. London, UK, Chapman and Hall, 1995; pp. 422-423.

8. Lee MM, King M. Effect of low molecular weight heparin on the elasticity of dog mucus. Proc 22nd European Cystic Fibrosis Conference, Berlin, Germany, 1998: 144.

9. Miller MD, Krangel MS. Biology and biochemistry of the chemokines. A family of chemotactic and inflammatory cytokines. Crit Rev Immunol 1992; 12: $17-46$.

10. Nelson RM, Cecconi O, Roberts WG, Aruffo A, Linhardt RJ, Bevilacqua MP. Heparin oligosaccharides binds L- and P-selectin and inhibit acute inflammation. Blood 1993; 82: 3253-3258.

11. Matzner Y, Marx G, Drexler R, Eldor A. The inhibitory effect of heparin and related glycosaminoglycans on neutrophil chemotaxis. Thrombos Haemostas 1984; 52: 134-137.

12. Reisenberg K, Schleffer F, Katz A, Levy R. Inhibition of superoxide production in human neutrophils by combinations of heparin and thrombolytic agents. $\mathrm{Br}$ Heart J 1996; 73: 14-19.

13. Faller B, Mely Y, Gerard D, Bieth JG. Heparininduced conformational change and activation of mucus proteinase inhibitor. Biochem 1992; 31: 82858290.

14. Warkentin TE, Chong BH, Greincher A. Heparininduced thrombocytopaenia: Towards consensus. Thrombos Haemostas 1998; 79: 1-7.

15. Jaques LB, Mahadoo J. Pharmacodynamics and clinical effectiveness of heparin. Sem Thromb Hemost 1978; 4: 298-325. 